\title{
NUMERICAL ANALYSIS OF HEAT TRANSFER IN MULTILAYERED SKIN TISSUE EXPOSED TO 5G MOBILE COMMUNICATION FREQUENCIES
}

\author{
Jagbir Kaur ${ }^{1, *}$, S.A. Khan²
}

\begin{abstract}
Rapid growth in wireless communications has triggered the advent of $5 \mathrm{G}$ mobile communication systems. The use of millimeter waves (30-300 GHz) in 5G system has generated global concern about its biological safety. In present paper, we have numerically analyzed the heat transfer in a 3D multilayered skin tissue exposed to 5G frequencies. The numerical scheme comprises coupling of solution of Maxwell's equation of wave propagation within tissue to Pennes' bioheat equation. Temperature variations are analyzed at $28 \mathrm{GHz}, 38 \mathrm{GHz}$, and $60 \mathrm{GHz}$. Additionally, electric field and specific absorption rate distribution are also studied. Highest values of electric field and specific absorption rateare estimated in epidermis layer of skin tissue. For all considered frequencies, highest transient temperature $\left(37.36^{\circ} \mathrm{C}\right)$ is predicted in subcutaneous fat layer of the skin. However, the steady state temperature is nearly same as core body temperature $\left(37^{\circ} \mathrm{C}\right)$. The results show that $5 \mathrm{G}$ mobile phones do not cause any thermal damage to the skin tissue and can be considered safe.
\end{abstract}

Keywords: Millimeter Waves, Bioheat Transfer, Multilayered Skin Tissue, 5G Mobile Phones

\section{INTRODUCTION}

Mobile phones have been an integral part of our lifestyle nowadays. The continuous increasing demand for high mobile data traffic and the proliferation of applications requiring high data rates have triggered the need for 5G mobile communication systems. As the data traffic is increasing tremendously, the sub $3 \mathrm{GHz}$ is becoming heavily crowded. On the other hand, millimeter wave $(\mathrm{mmW})$ frequencies $(30-300 \mathrm{GHz})$ are considered promising for $5 \mathrm{G}$ communication networks due to the massive amount of raw bandwidth and potential multigigabit-per-second $(\mathrm{Gb} / \mathrm{s})$ data rates [1]. This "next generation" mobile commutation system will be capable of responding to an avalanche of traffic, an upsurge in the number of connected devices, and the large variety of use cases. Despite numerous benefits, $5 \mathrm{G}$ mobile communication systems have generated a concern among the researchers if they are biologically safe. The electromagnetic (EM) energy carried by mmWs is transferred to the biological tissue, which results in ion acceleration and collisions among molecules. Consequently, the local temperature of the tissue rises [2]. A small change of $1-5^{\circ} \mathrm{C}$ in tissue may cause malfunctions of organs [3].

Since mmWs have very short wavelength, their penetration in the biological medium is superficial $[4,5]$.The shallow penetration of $5 \mathrm{G}$ frequencies suggests that they can only infiltrate the skin layer of human body. Thus the EM energy associated with the mmWs will be absorbed within the skin layer; and the temperature changes due to absorption of the radiation will occur in skin. Thermal changes in humans due to RF and microwaves have been reported in many previous studies [6-9]. Kojima et al. studied the ocular damage due to thermal changes in eyes exposed to mmWs [10]. Stewart and co-workers investigated skin heating due to prolonged exposure to $94 \mathrm{GHz}$ [11].

This paper was recommended for publication in revised form by Regional Editor Erdal Çetkin

${ }^{1}$ Research Scholar, Department of Research and Development, I.K. Gujral Punjab Technical University, Jalandhar, Punjab, India.

${ }^{2}$ Shiv Shankar Institute of Engineering and Technology, Patti, Tarn taran, Punjab, India.

${ }^{*} E$-mail address:jagbirk@gmail.com

Orcid ID: 0000-0001-8565-5134, 0000-0001-9937-0084

Manuscript received 13 January 2019, Accepted 18 October 2019 
Sasaki et al. used Monte Carlo simulations to investigate the temperature changes in skin tissue due to $\mathrm{GHz}$ exposure [12]. However,more investigations are needed for comprehensive knowledge of thermal effects of mmWs.

The present study provides the detailed analysis of thermal response of a three-dimensional multilayered skin tissue to $5 \mathrm{G}$ mobile communication frequencies. The frequencies selected for the analysis viz. $28 \mathrm{GHz}, 38 \mathrm{GHz}$ and $60 \mathrm{GHz}$, are promising frequencies for $5 \mathrm{G}$ mobile communications $[13,14]$. The skin tissue is exposed to the mmWs from the microstrip antenna of the mobile phone. The output power transmitted by the half wave dipole microstrip antenna is compliant with the power density limit $\left(10 \mathrm{~W} / \mathrm{m}^{2}\right)$ set by International Commission on Non-Ionizing Radiation Protection (ICNIRP) [15]. The obtained temperature variations suggest whether 5G mobile phones are safe for the users.

\section{METHODS}

A 3D skin model comprising four different layers viz. epidermis, dermis, subcutaneous fat,and inner tissue (muscle) is exposed to $5 \mathrm{G}$ mobile communication frequencies $(28 \mathrm{GHz}, 38 \mathrm{GHz}$, and $60 \mathrm{GHz}$ ) (Fig.1). The microstrip antenna is placed $2 \mathrm{~cm}$ away from epidermis layer. The EM energy is transmitted by the lumped port of the antenna and this energy is absorbed by the multilayered skin tissue. Physical and dielectric properties of the different layers of skin tissue are listed in Table 1 and Table 2 respectively. A finite element method (FEM) based software; COMSOL Multiphysics has been employed to numerically analyze the electric field, SAR and temperature variations within the tissue. The analysis is carried in two steps: (a) electromagnetic analysis and (b) bioheat analysis. In electromagnetic analysis electric field and SAR are determined, and the temperature variations are studied in bioheat analysis.

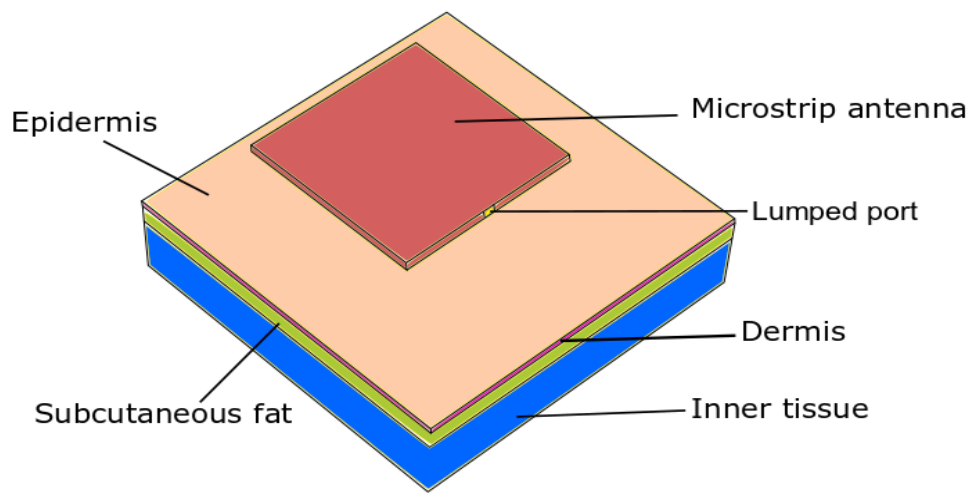

Figure 1. Schematic geometry of multilayered skin tissue with microstrip patch antenna.

Table 1.Physical and thermal properties of skin layers [16]

\begin{tabular}{|l|l|l|l|l|l|}
\hline Tissue & $\begin{array}{l}\text { Specific } \\
\text { Heat, } \mathrm{C}_{\mathrm{p}} \\
(\mathrm{J} / \mathrm{kg} . \mathrm{K})\end{array}$ & $\begin{array}{l}\text { Thermal } \\
\text { conductivity, } \\
\mathrm{K}(\mathrm{W} / \mathrm{m} . \mathrm{K})\end{array}$ & $\begin{array}{l}\text { Mass density, } \\
\rho\left(\mathrm{kg} / \mathrm{m}^{3}\right)\end{array}$ & $\begin{array}{l}\text { Perfusion rate, } \\
\omega(1 / \mathrm{s})\end{array}$ & $\begin{array}{l}\text { Thickness, } \\
\mathrm{x}(\mathrm{m})^{\mathrm{a}}\end{array}$ \\
\hline Epidermis & 3600 & 0.235 & 1190 & 0 & $80^{*} 10 \mathrm{E}-6$ \\
\hline Dermis & 3300 & 0.445 & 1116 & 1.5 & 0.002 \\
\hline \begin{tabular}{l} 
Subcutaneous Fat \\
\hline $\begin{array}{l}\text { Inner tissue } \\
\text { (muscle) }\end{array}$
\end{tabular} & 2700 & 0.185 & 971 & 1.5 & 0.01 \\
\hline
\end{tabular}




\section{Electromagnetic Analysis}

Electric field distribution and SAR are calculated within the exposed tissue using electromagnetic equations. Following assumptions are made for simplification of the problem:

1. Electromagnetic wave propagation is modeled in three dimensions.

2. Interaction between skin tissue and the electromagnetic waves takes place in open region.

3. The free space surrounding the calculated domain is truncated by scattering boundary condition.

4. The dielectric properties of skin tissue are assumed constant for each layer.

As the skin tissue is exposed to mmWs, EM waves propagate inside the skin tissue. Maxwell's equation governs the propagation of EM waves inside a biological tissue, and electric field (E) inside the tissue can be determined by equation $[18,19]$ :

$$
\nabla \times \frac{1}{\mu_{r}}(\nabla \times E)-k_{0}^{2}\left(\varepsilon_{r}-\frac{j \sigma}{\omega \varepsilon_{0}}\right) E=0
$$

where $\mu_{r}$ is relative magnetic permeability, $\varepsilon_{r}$ is relative permittivity, $\varepsilon_{0}=8.8542 \times 10^{-12} \mathrm{~F} / \mathrm{m}, k_{0}$ is the free space wave number, $\sigma$ is conductivity of tissue and $\omega$ is angular frequency.

\section{Boundary conditions}

The microstrip patch antenna radiates electromagnetic energy which strikes the skin tissue with a specific power.At the bottom of patch antenna; the stimulator employs a lumped port between two patches in order to generate an electromagnetic field. Lumped port boundary condition is defined as [20]:

$$
Z_{\text {in }}=\frac{V_{1}}{I_{1}}=\frac{E_{1} l}{I_{1}}
$$

where $Z_{\text {in }}$ is the input impedance, $V_{1}$ is the voltage along the edges, $I_{1}$ is the electric current magnitude, $E_{1}$ is the electric field along the source edge, and $l$ is the edge length.

A perfect electric conductor boundary condition is applied to the side walls of the patch, so that the lumped port acts as a cavity [21]:

$$
n \times E=0
$$

In order to truncate the space outside the calculated domain, scattering boundary condition is applied on outer edges of modeled region (Fig. 2), as

$$
n \times(\nabla \times E)-j k n \times(E \times n)=-n \times\left(E_{0} \times j k(n-k)\right) \exp (-j k . r)
$$

where $k$ is the wave number, $\mathrm{n}$ is normal vector, $j=\sqrt{-1}$, and $E_{0}$ is the electric field intensity of incident plane wave.

The existence of electric field within skin model conveys that EM energy is deposited in the tissues. The energy absorbed by the tissues is expressed in terms of SAR. The local SAR can be calculated using the relation [22, $23,24]$

$$
S A R=\sigma|E|^{2} / \rho
$$

where $\sigma$ is the conductivity and $\rho$ is mass density of the tissue, and $\mathrm{E}$ is the electric field within the tissue exposed to $5 \mathrm{G}$ frequencies. 
Table 2. Dielectric properties of skin layers at different frequencies [25]

\begin{tabular}{|c|c|c|c|c|c|c|}
\hline & \multicolumn{2}{|c|}{$28 \mathrm{GHz}$} & \multicolumn{2}{|c|}{$38 \mathrm{GHz}$} & \multicolumn{2}{|c|}{$60 \mathrm{GHz}$} \\
\hline & $\begin{array}{l}\text { Permittivity } \\
\varepsilon_{\mathrm{r}}\end{array}$ & $\begin{array}{l}\text { Conductivity } \\
\sigma(\mathrm{S} / \mathrm{m})\end{array}$ & $\begin{array}{l}\text { Permittivity } \\
\varepsilon_{\mathrm{r}}\end{array}$ & $\begin{array}{l}\text { Conductivity } \\
\sigma(\mathrm{S} / \mathrm{m})\end{array}$ & $\begin{array}{l}\text { Permittivity } \\
\varepsilon_{\mathrm{r}}\end{array}$ & $\begin{array}{l}\text { Conductivity } \\
\sigma(\mathrm{S} / \mathrm{m})\end{array}$ \\
\hline Epidermis & 3.39 & 0.3 & 3.37 & 0.78 & 3.32 & 1.78 \\
\hline Dermis & 4.28 & 18.2 & 4.24 & 20 & 4.15 & 25.6 \\
\hline $\begin{array}{l}\text { Subcutaneous } \\
\text { fat }\end{array}$ & 3.76 & 7.1 & 3.73 & 8.9 & 3.67 & 10.95 \\
\hline $\begin{array}{l}\text { Inner tissue } \\
\text { (muscle) }\end{array}$ & 24.4 & 33.6 & 19.1 & 41.8 & 12.9 & 52.8 \\
\hline
\end{tabular}

\section{Bioheat Analysis}

The heat transferred to the skin tissue is calculated using Pennes' bioheat equation, the pioneer mathematical model for analyzing heat conduction in the biological tissues. This mathematical model has been widely used in many investigations to predict the temperature changes in biological medium [16, 17, 26, 27, 28]. It is expressed as [29]:

$$
\rho C_{p} \frac{\partial T}{\partial t}=\nabla \cdot(K \nabla T)+\rho_{b} C_{p, b} \omega_{b}\left(T_{b}-T\right)+Q_{m}+Q_{\text {ext }}
$$

where $\rho, C_{p}$ and $K$ are the density, specific heat at constant pressure, and the thermal conductivity of tissue, respectively. $\rho_{b}$ and $C_{p, b}$ are the density and specific heat(at constant pressure) of the blood, respectively. $\omega_{b}$ is the blood perfusion rate; $T$ and $T_{b}$ are tissue and blood temperatures, respectively. $Q_{m}$ is metabolic heat generation in the tissue and $Q_{e x t}$ is the external heat source term (electromagnetic heat-source density). The term $\rho_{b} C_{b} \omega_{b}\left(T_{b}-T\right)$ describes the heat caused by convection and $\nabla .(K V T)$ represents the heat conduction inside the skin tissue. $Q_{\text {ext }}$ represents the resistive heat generated by the electromagnetic source and is expressed as [30]:

$$
Q_{\text {ext }}=\frac{1}{2} \sigma|E|^{2}
$$

where $\sigma$ is the conductivity of the tissue and $E$ is the electric field within the tissue exposed to mmWs. $Q_{m}$ is neglected and assumed zero in the analysis, since we aim to evaluate the effect of electromagnetic energy associated with mmWs only .

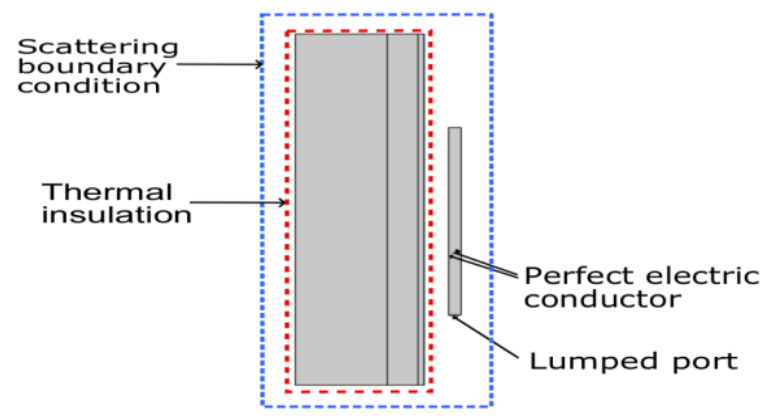

Figure 2. Boundary conditions for numerical analysis. 
Following assumptions are made for bioheat transfer analysis:

1. Each layer of tissue is a biomaterial with constant thermal properties.

2. No chemical reaction takes place in the considered domain.

3. The blood perfusion rate remains constant for each layer.

4. There is no change of phase of matter within the tissue.

In the analysis, bioheat equation (Eq. (6)) is coupled to the solution of Maxwell's equation. Substituting values of E, $Q_{\text {ext }}$ is calculated using Eq. (7) and temperature rise is determined using Eq. (6).

\section{Boundary conditions}

The temperature of human body is assumed uniform and its initial value is $37^{\circ} \mathrm{C}$. Therefore, initial condition for bioheat transfer is:

$$
\mathrm{T}=37^{\circ} \mathrm{C} \text { at } \mathrm{t}=0 \text { and } \frac{\partial \mathrm{T}}{\partial \mathrm{t}}=0 \text { at } \mathrm{t}=0
$$

No heat is exchanged between the calculated domain and the outer region. Hence, thermal insulation boundary condition is employed on the outer boundaries of the model (Fig. 2) [19]:

$$
n \cdot(K \nabla T)=0
$$

\section{Procedure for Simulation and Grid Independence}

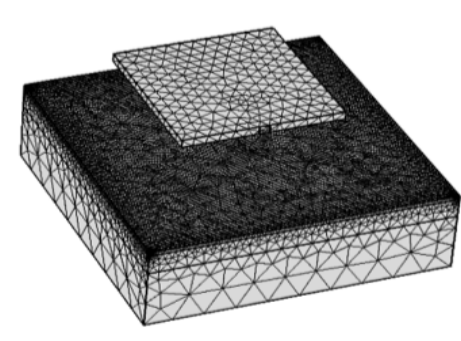

(a)

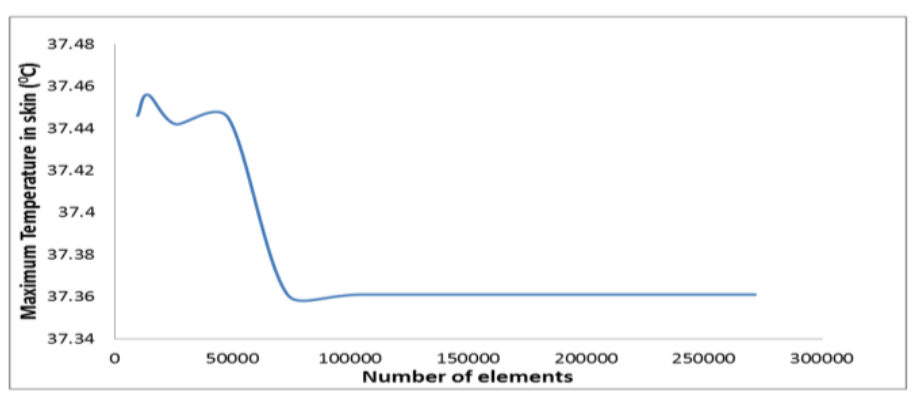

(b)

Figure 3. (a) Tetrahedral mesh and (b) grid independence for calculated domain used in FEM analysis.

In numerical simulation, the electric field at every point within calculated domain is determined in electromagnetic analysis. The value of electric field is used to calculate the heat generated by the electromagnetic source (Eq. (7)). The temperature at every point within domain is determined using electromagnetic field at that point and the steps are repeated until the steady state of temperature is reached. The numerical domain is discretized using tetrahedral elements with a total number of 140272 elements. A grid independence test is performed to approximate the number of elements above which the solution is independent of mesh elements (Fig. 3b). The grid independence is attained for the number of elements more than 73130. Higher numbers of elements are not tested due to lack of computational memory and performance. 


\section{RESULTS AND DISCUSSION}

\section{Validation}

Considering the ethical restrictions, it is not possible to directly measure the electric field and temperature distribution inside the human body. Therefore, to validate the accuracy of the numerical simulation used in present study, a modified case of simulation results is verified against the numerical results with same geometric model obtained by Nishizawa and Hashimoto [24]. Fig. 4a shows 2D schematic geometry of human abdomen used in validation case. The model consists of three layers viz. skin, fat and muscle. The plane wave E (TM) of frequency $1300 \mathrm{MHz}$ and power density $1 \mathrm{~mW} / \mathrm{cm}^{2}$, propagating along positive X-direction is incident on left side of model. The local SAR is plotted along cross sectional line through the abdomen; the graph (Fig. 4b) shows good agreement in SAR values between present solution and that of Nishizawa and Hashimoto. Small deviations occurring between two results may be due to different numerical scheme used and input dielectric properties of the tissues. This encouraging comparison gives confidence in accuracy of the simulation used in present study.

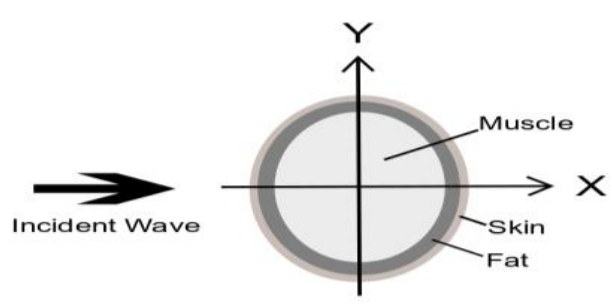

(a)

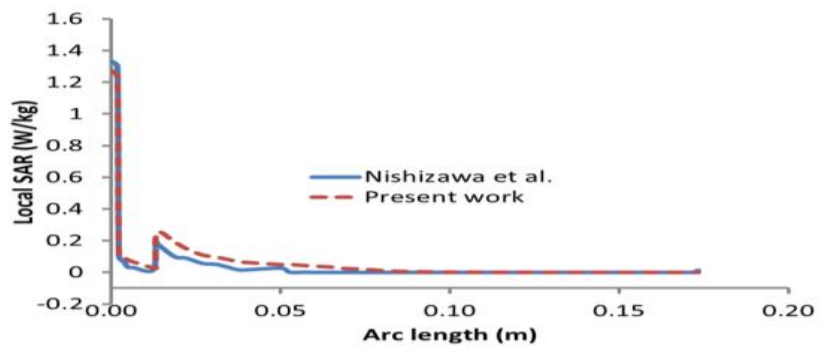

(b)

Figure 4. (a) 2-dimensional geometry for validation of model from Nishizawa and Hashimoto [24] (b) Comparison of local SAR distribution calculated by present numerical simulation and that by Nishizawa and Hashimoto

\section{Electric Field and SAR Distribution}

Penetration of electromagnetic radiation within the layers of skin tissue generates electric field inside the skin. Fig.5 shows the steady state electric field distribution in the multilayered skin tissue exposed to 5G mobile communication frequencies. The electric field distribution pattern is different in each exposure case; At $28 \mathrm{GHz}$ and $38 \mathrm{GHz}$ electric field spreads to larger areas than at $60 \mathrm{GHz}$ and electric field hotspots are located in the vicinity of lumped port of microstrip antenna. Maximum steady state surface electric field at $28 \mathrm{GHz}, 38 \mathrm{GHz}$ and $60 \mathrm{GHz}$ is $312.51 \mathrm{~V} / \mathrm{m}, 478.41 \mathrm{~V} / \mathrm{m}$ and $461 \mathrm{~V} / \mathrm{m}$ respectively; which conveys that at $38 \mathrm{GHz}$ maximum electromagnetic energy is transferred to the skin tissue. The electromagnetic energy absorbed by a biological tissue is expressed in terms of SAR (W/kg). The local SAR is calculated using Eq. (3). Since SAR at any point is directly proportional to electric field at that point, local SAR distribution pattern can be assumed similar to electric field distribution pattern.

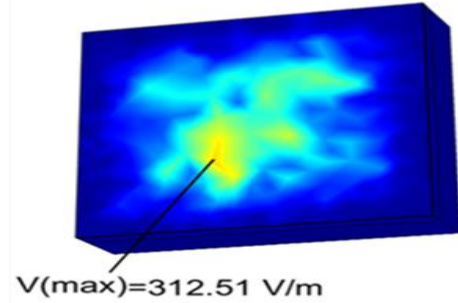

(a)

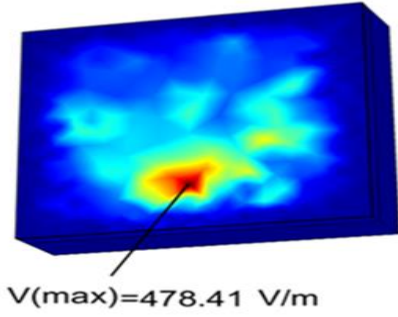

(b)

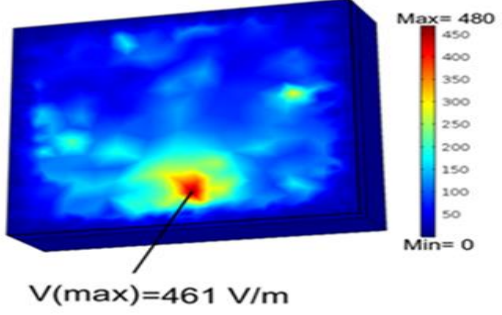

(c)

Figure 5. Steady state electric field distribution in skin tissue at (a) $28 \mathrm{GHz}$, (b) $38 \mathrm{GHz}$, and (c) $60 \mathrm{GHz}$. 
Fig. 6 portrays the variations in electric field and local SAR at different frequencies along cross sectional line (arc length) passing through the different layers of skin tissue. The electric field and SAR curves show similar pattern at a particular frequency. Greatest electric field and local SAR $(1050 \mathrm{~V} / \mathrm{m}$ and $725 \mathrm{~W} / \mathrm{kg}$ respectively) at $38 \mathrm{GHz}$ and lowest (214.3 V/m and $42.2 \mathrm{~W} / \mathrm{kg}$ respectively) at $60 \mathrm{GHz}$ suggest that EM energy absorbed is maximum at $38 \mathrm{GHz}$ and least at $60 \mathrm{GHz}$. In all the exposure cases, the peak values of electric field and SAR are estimated in epidermis layer of skin. Beyond epidermis, the magnitude of electric field and SAR falls rapidly; further than dermis, electric field and SAR are almost zero. The penetration depth of electric field is approximately $2 \mathrm{~mm}$ within the skin tissue. This result is in agreement with the fact that the energy absorbed due to $5 \mathrm{G}$ radiation exposure is superficial.

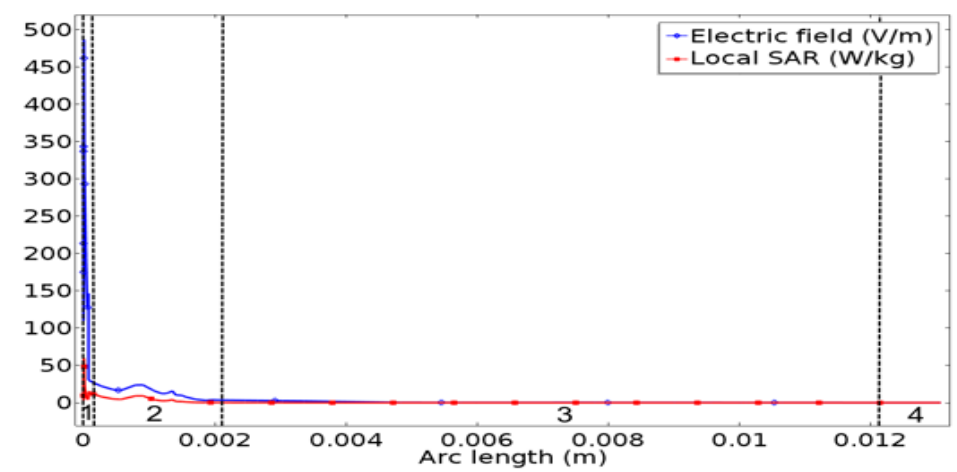

(a)

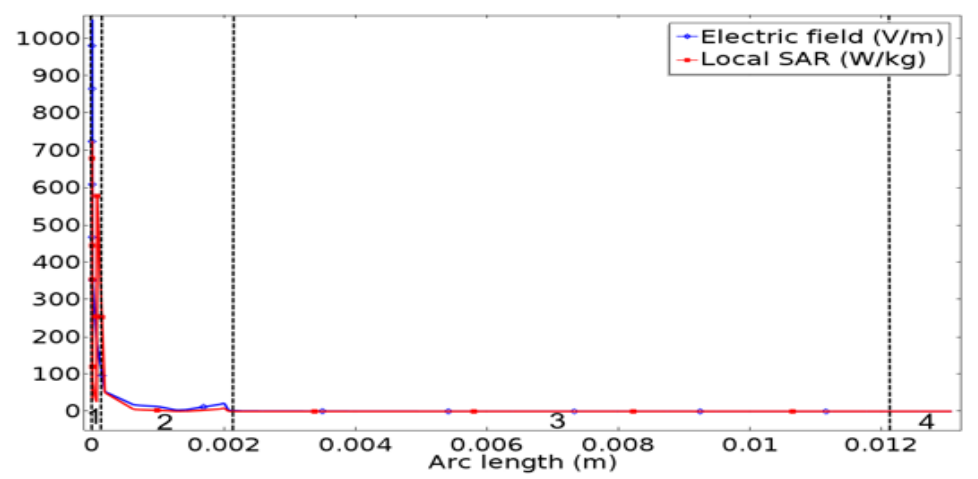

(b)

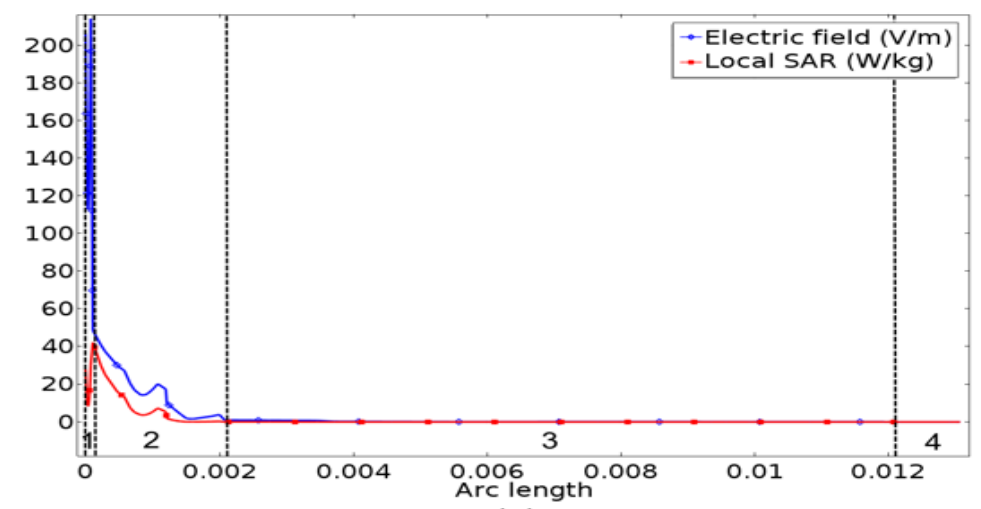

(c)

Figure 6. Electric field and local SAR distribution versus arc length at (a) $28 \mathrm{GHz}$, (b) $38 \mathrm{GHz}$, and (c) $60 \mathrm{GHz}$; 1:epidermis, 2: dermis, 3: subcutaneous fat, 4: inner tissue. 


\section{Temperature Distribution}

The EM energy absorbed within the tissue produces oscillations in the molecules, which consequently raise the local temperature of the tissue. The temperature distribution within multilayered skin tissue is estimated using Pennes' bioheat equation. Fig. 7 shows the steady state temperature distribution in skin tissue exposed to 5G frequencies from a microstrip patch antenna. The initial skin temperature considered for analysis is $34^{\circ} \mathrm{C}$ and the steady state temperature is slightly higher than core body temperature $\left(37^{\circ} \mathrm{C}\right)$ for all exposure frequencies. However, the highest steady state temperature $\left(37.006^{\circ} \mathrm{C}\right)$ is estimated at $60 \mathrm{GHz}$. This finding suggests that exposure to mmWs do not alter the skin temperature significantly, hence the possibility of thermal hazards due exposure to $5 \mathrm{G}$ frequencies is negligible.

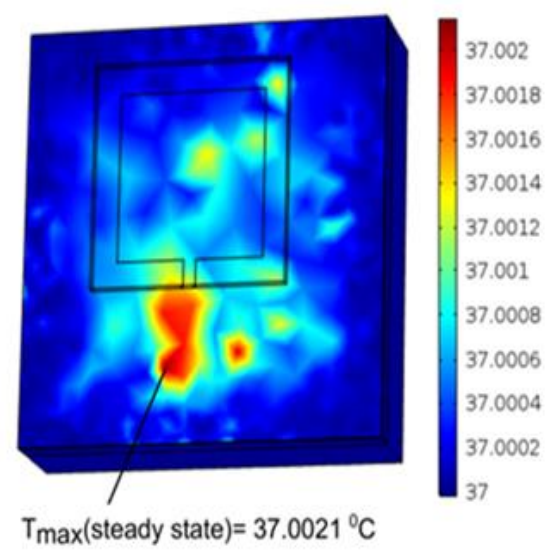

(a)

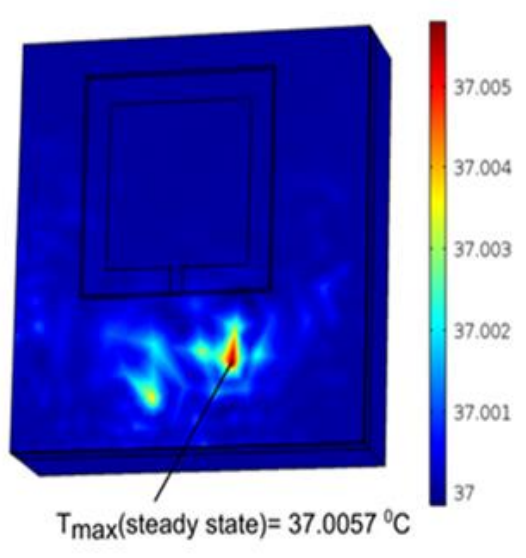

(b)

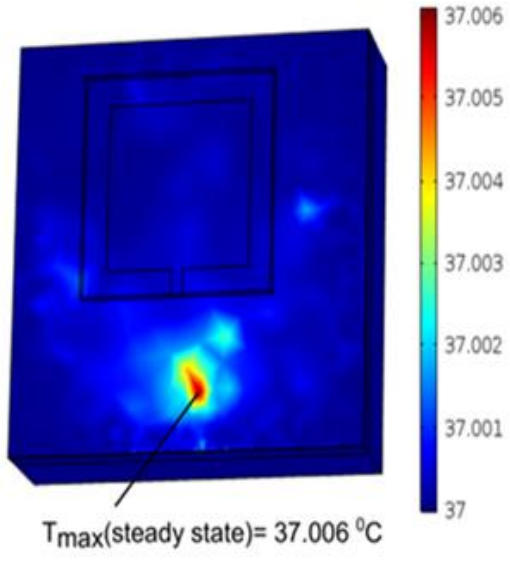

(c)

Figure 7. Steady state temperature distribution in skin tissue at (a) $28 \mathrm{GHz}$, (b) $38 \mathrm{GHz}$, and (c) $60 \mathrm{GHz}$.

Fig. 8 illustrates the temperature variations at various instants of $\mathrm{mmW}$ exposure along cross sectional (arc length) line passing through different layers of skin tissue. The skin tissue responds immediately as it is exposed to the radiation. The temperature within the different layers rises very quickly; temperature achieves its peak value $\left(37.36^{\circ} \mathrm{C}\right)$ at $2 \mathrm{~s}$ of the exposure. The highest temperature is estimated in subcutaneous fat layer. Low thermal conductivity of subcutaneous fat layer (Table 1) can be held responsible for occurrence of temperature peak in this layer. However the temperature falls quickly, and at $10 \mathrm{~s}$ of exposure the temperature falls below $37^{\circ} \mathrm{C}$ within subcutaneous fat. This behavior of temperature curve indicates the onset of blood perfusion, which sweeps the heat generated locally in the tissue. Thereafter, trivial changes in the temperature take place and it attains its steady state. This may be noted that the temperature behavior is almost identical at all the exposure frequencies, except small variations in the temperature curves at $2 \mathrm{~s}$. This finding signifies that thermal response of the skin tissue does not vary significantly with $5 \mathrm{G}$ frequencies. 
Journal of Thermal Engineering, Technical Note, Vol. 7, No. 2, Special Issue 13, pp. 103-116, February, 2021

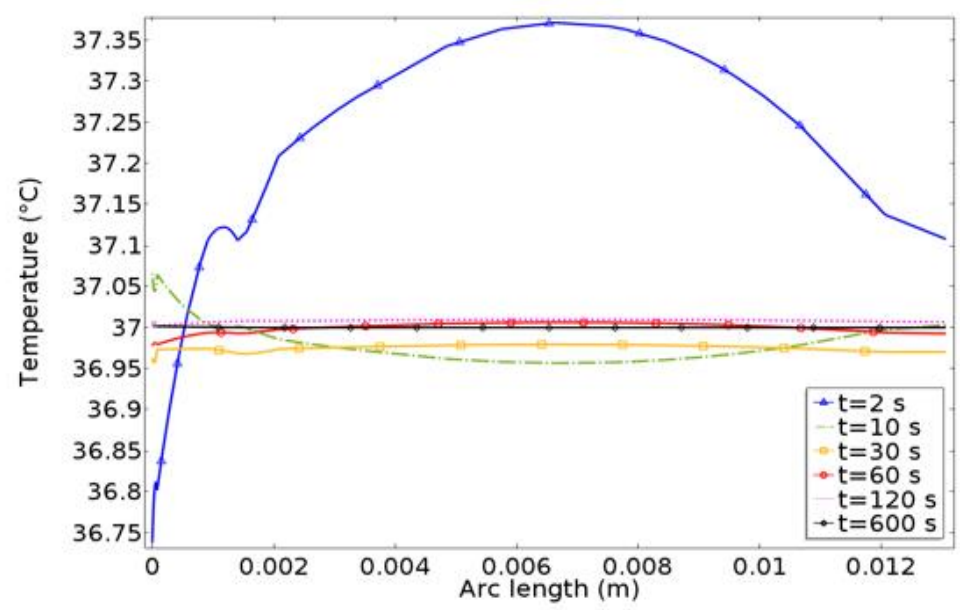

(a)

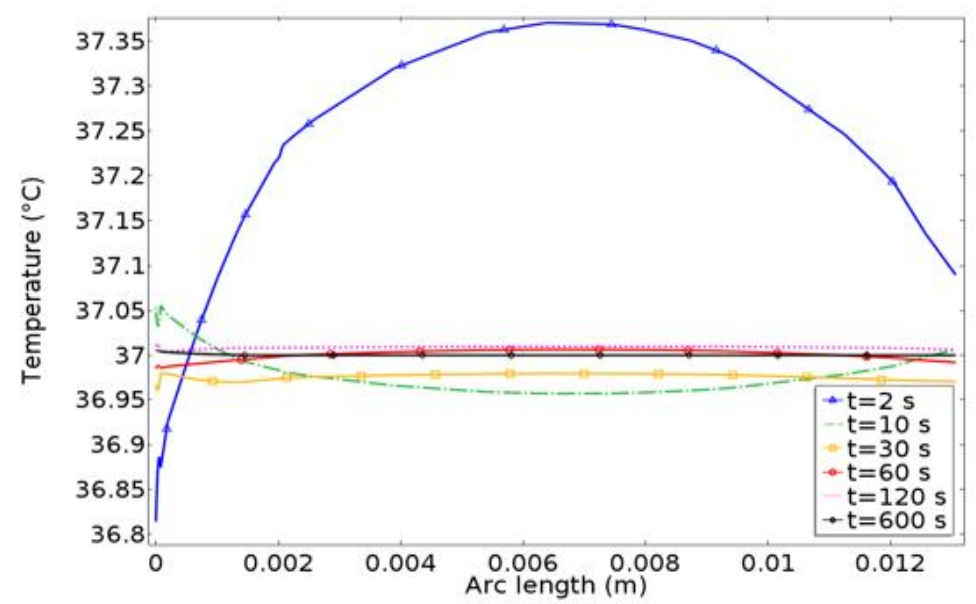

(b)

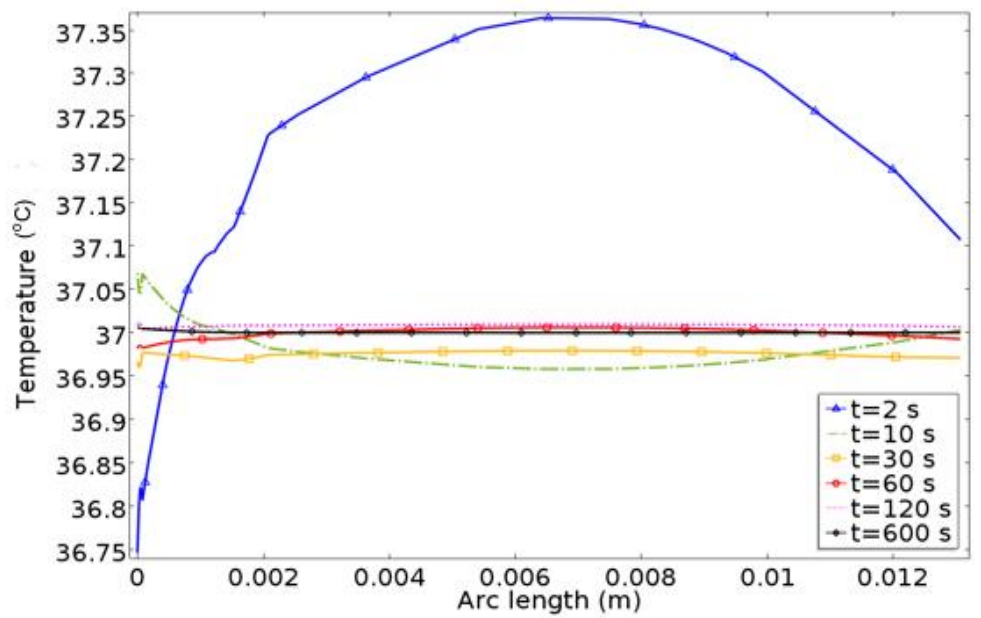

(c)

Figure 8. Temperature distribution at different instants of exposure period versus arc length at (a) $28 \mathrm{GHz}$, (b) 38 GHz, and (c) $60 \mathrm{GHz}$; 1:epidermis, 2: dermis, 3: subcutaneous fat, 4: inner tissue. 
Fig. 9 portrays the temperature changes in different layers w.r.t. the exposure duration at $60 \mathrm{GHz}$. The highest temperature $\left(37.361^{\circ} \mathrm{C}\right)$ is estimated in subcutaneous fat layer, which may be due to low thermal conductivity of this layer. The peak temperatures in epidermis and dermis layer are $37.205^{\circ} \mathrm{C}$ and $37.160^{\circ} \mathrm{C}$ respectively. The peaks in temperature curves occur at $2 \mathrm{~s}$ of exposure, thereafter, temperature drops very quickly below $37^{\circ} \mathrm{C}$, which is core body temperature. Steady state in temperature $\left(37.006^{\circ} \mathrm{C}\right)$ is attained after $140 \mathrm{~s}$ of exposure.

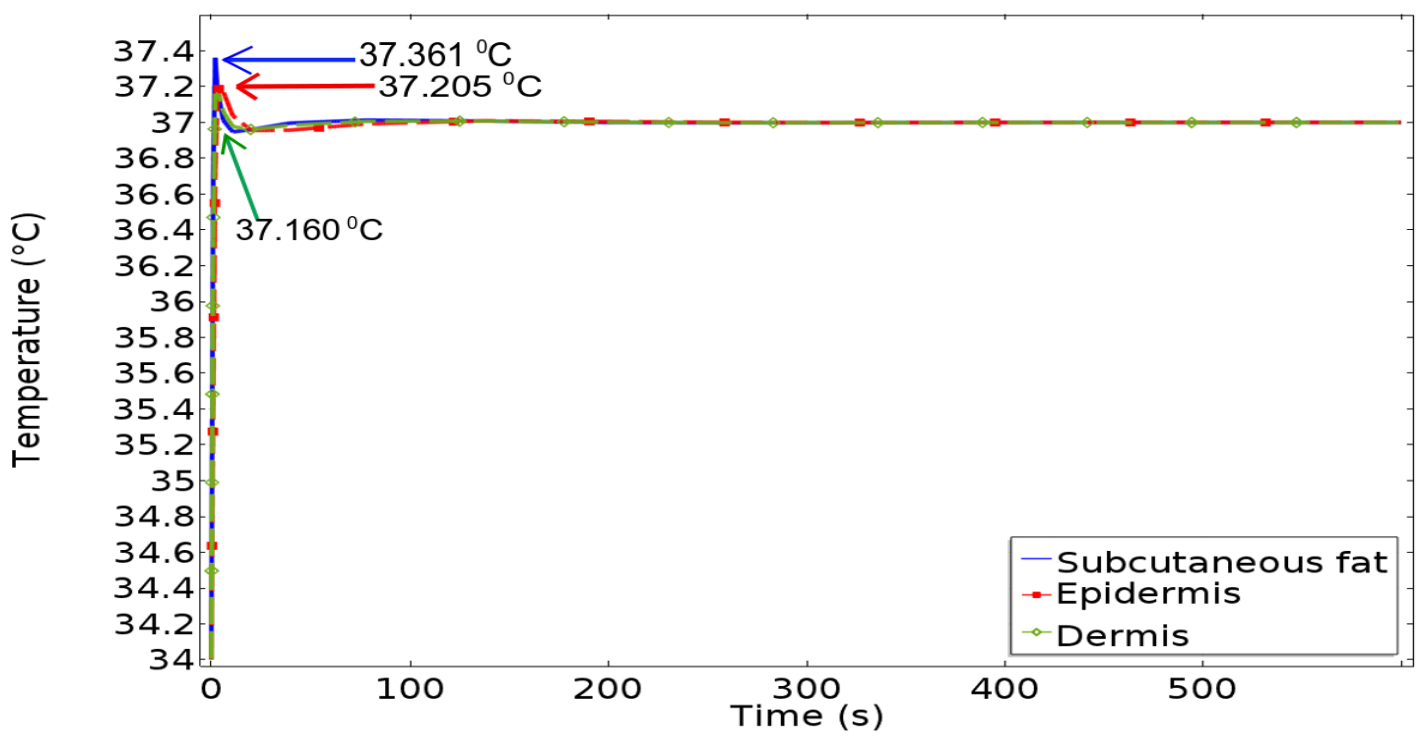

Figure 9. Temperature distribution versus exposure duration within different skin layers at $60 \mathrm{GHz}$.

\section{Role of Dielectric Properties and Their Frequency Dependence}

Dielectric properties play an important role in determining the energy deposition and hence, temperature elevation in the biological matter exposed to electromagnetic fields. Eq. (1), Eq. (5) and Eq. (7) show that electric field, SAR and the temperature variations in exposed tissue depend on the permittivity and conductivity of the tissue. The complex valued, relative permittivity of a tissue is expressed as [31]:

$$
\varepsilon^{*}=\varepsilon^{*}=\varepsilon_{r}-\frac{i \sigma}{\omega \varepsilon_{0}}=\varepsilon_{r}{ }^{\prime}-i \varepsilon_{r}{ }^{\prime \prime}
$$

where $\varepsilon_{r}{ }^{\prime}=\varepsilon_{r}$ and $\varepsilon_{r}{ }^{\prime \prime}=\frac{\sigma}{\omega \varepsilon_{0}}$.

The complex conductivity and complex permittivity are related by [31]:

$$
\sigma^{*}=i \omega \varepsilon^{*}
$$

$\varepsilon^{*}$ and $\sigma^{*}$ vary with frequency and such a variation is called dispersion. Biological materials show many dispersions over a wide range of frequencies [32]. $\alpha$ dispersion exhibited at low frequencies, which is associated with ionic diffusion process at cellular membranes. $\beta$ dispersion, in hundreds of kilohertz region, is due to polarization of cellular membranes, proteins and other organic molecules. In gigahertz region, $\gamma$ dispersion is due to polarization of water molecules in the tissue. The water content in biological tissues exists in two forms: bulk and hydrated. Hydration rate is very high in tissues and can reach $80 \%$ [32]. The volume fraction of bulk water $18 \%$ in epidermis and 28\% in dermis [32]. Feldmen et al. showed that in GHz region, frequency dependence of dielectric properties is function of bulk water content [33]. Epidermis has lower water content, thus it has very small variations with 
frequency. However, dermis layer has slightly higher frequency dependence, due to its bigger water content. Studies revealed that subcutaneous fat has water content of $18-28.7 \%[34,35,36]$. Thus, frequency dependence of fat layer lies between that of dermis and epidermis.

Fig. 8 shows that the temperature curves for skin tissue are almost identical for all the exposed frequencies. This result is in agreement with the fact that in $\mathrm{GHz}$ range, the dielectric properties of skin layers vary slightly with frequency. Hence, for each tissue layer, temperature predicted at different frequencies is almost same.

\section{CONCLUSIONS}

The explosive growth in mobile communication systems has called for $5 \mathrm{G}$ era. The use of $\mathrm{mmW}$ frequencies in $5 \mathrm{G}$ communication systems has generated concerns about their biological safety. Thermal analysis of exposed tissues is particularly important to evaluate the health risks associated with $\mathrm{mmW}$ exposure. Due to "very small" wavelength, the penetration of mmWs is very small. Thus, the potential thermal hazards due to $\mathrm{mmW}$ exposure can occur in skin. The present study evaluates the electric field, local SAR and temperature variations within a multilayered skin tissue exposed to $5 \mathrm{G}$ frequencies in $\mathrm{mmW}$ range. We have estimated the electric field and local SAR at mmW frequencies for exposure power density limit $\left(10 \mathrm{~W} / \mathrm{m}^{2}\right)$ set by ICNIRP. The electric field and SAR distribution exhibit similar pattern. Maximum electric field is estimated in skin when the exposure frequency is $38 \mathrm{GHz}$; while lowest electric field is predicted at $28 \mathrm{GHz}$. Also, SAR which measures the EM energy absorbed by skin tissue is maximum at $38 \mathrm{GHz}$ and is minimum at $60 \mathrm{GHz}$.

In addition to electric field and SAR analysis, it is necessary to determine the temperature alterations occurred in the exposed tissue for complete investigation of thermal effects of 5G frequencies. We have used Pennes' bioheat equation to calculate the temperature variations in exposed multilayer skin tissue. It is found that the SAR and temperature distribution do not follow a similar pattern. Highest value of SAR is predicted in epidermis layer, whereas highest temperature peak is estimated in the subcutaneous fat layer. For all the exposure frequencies, highest transient temperature is predicted at $2 \mathrm{~s}$ of exposure. Highest transient temperature in epidermis layer, dermis layer and subcutaneous fat is $37.20^{\circ} \mathrm{C}, 37.16^{\circ} \mathrm{C}$ and $37.36^{\circ} \mathrm{C}$ respectively. Highest temperature in subcutaneous layer is due to lower thermal conductivity of this layer. The temperature falls very quickly due to onset of blood perfusion and achieves its steady state (approximately $37^{\circ} \mathrm{C}$ ), which is core body temperature. In addition to blood perfusion and thermal conductivity, the dielectric properties of skin layers play an important role in estimating the temperature variations. In $\mathrm{GHz}$ region, the dielectric properties do not vary significantly with exposure frequency. As the result, temperature variations are almost similar at different frequencies of exposure.

This study reveals that the maximum temperature change in skin exposed to $5 \mathrm{G}$ frequencies is $0.36^{\circ} \mathrm{C}$, and the temperature spike is very short lived. The temperature rise is too small to cause any thermal damage to the tissue. The results indicate that the mmWs cannot cause thermal injuries in skin and may be considered safe for 5G mobile communications.

\section{NOMENCLATURE}

$\begin{array}{ll}\text { C } & \text { Specific heat capacity, } \mathrm{J} /(\mathrm{kg} . \mathrm{K}) \\ \mathrm{E} & \text { Electric field intensity, } \mathrm{V} / \mathrm{m} \\ \mathrm{I} & \text { Electric current, A } \\ \mathrm{K} & \text { Thermal conductivity, W/(m.K) } \\ \mathrm{k} & \text { Wave number, } 1 / \mathrm{m} \\ \mathrm{l} & \text { Edge length, } \mathrm{m} \\ \mathrm{n} & \text { Normal vector } \\ \mathrm{Q} & \text { Heat generation, } \mathrm{W} / \mathrm{m}^{3} \\ \mathrm{SAR} & \text { Specific Absorption Rate, W/kg } \\ \mathrm{T} & \text { Temperature, }{ }^{\circ} \mathrm{C}\end{array}$




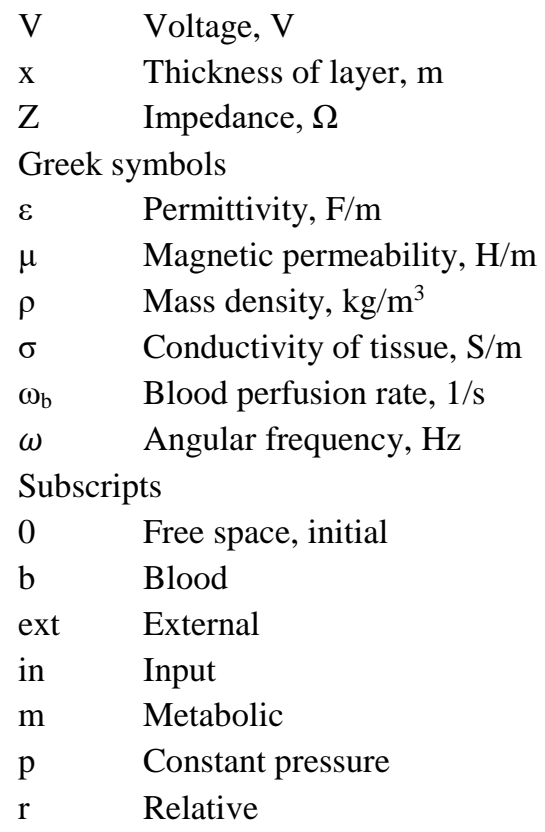

Conflict of Interest: The authors declare that they have no conflict of interest.

\section{REFERENCES}

[1] Xiang W, Zheng K, and Shen X. 5G Mobile communications. Switzerland: Springer; 2017. doi: 10.1007/978-3319-34208-5

[2] Challis LJ. Mechanisms for interaction between RF fields and biological tissue. Bioelectromagnetics Suppl 2005; 7: S98-S106. https://doi.org/10.1002/bem.20119

[3] Stuchly MA. Health Effects of Exposure to Electromagnetic Fields. IEEE Aerospace Applications Conference Proceedings 1995; 351-368. doi: 10.1109/AERO.1995.468891

[4] Gandhi OP, and Riazi A. Absorption of millimeter waves by human beings and its biological implications. IEEE Trans Microwave Theory Tech 1986; 34(2): 228-235. doi:10.1109/TMTT.1986.1133316

[5] Zhadobov M, Chahat N, Sauleau R, Le Quément C, and Le Dréan Y. Millimeter-wave interactions with the human body: State of knowledge and recent advances. Int J Microwave Wireless Technol 2011; 3(2): 237-247. https://doi.org/10.1017/S1759078711000122

[6] Gandhi OP, Lazzi G, Furse CM. Electromagnetic absorption in the human head and neck for mobile telephones at 835 and $1900 \mathrm{MHz}$. IEEE Trans. Microwave Theory Tech 1996; 44: 1884-1897. doi: 10.1109/22.539947

[7] Wang J, and Fujiwara O. FDTD computation of temperature rise in the human head for portable telephones. IEEE Trans Microwave Theory Tech 1999; 47 (8): 1528-1534. doi: 10.1109/22.780405

[8] Bernardi P, Cavagnaro M, Pisa S, Piuzzi E. Specific absorption rate and temperature elevation in a subject exposed in the far-field of radio-frequency sources operating in the 10-900-MHz range. IEEE Transactions on Biomedical Engineering 2003; 50: 295-304. doi: 10.1109/TBME.2003.808809

[9] Bakker JF, Paulides MM, Neufeld E, Christ A, Kuster N, Rhoon GCv. Children and adults exposed to electromagnetic fields at the ICNIRP reference levels: theoretical assessment of the induced peak temperature increase. Phys Med Biol 2011; 56: 4967-4989. doi:10.1088/0031-9155/56/15/020

[10] Kojima M, Suzuki Y, Sasaki K, Taki M, Wake K, Watanabe S, Mizuno M, Tasaki T, Sasaki H. Ocular Effects of Exposure to 40, 75, and $95 \mathrm{GHz}$ Millimeter Waves. J Infrared, Milli, Terahz Waves 2018; 39(9): 912-925. https://doi.org/10.1007/s10762-019-00641-w. 
Journal of Thermal Engineering, Technical Note, Vol. 7, No. 2, Special Issue 13, pp. 103-116, February, 2021

[11] Stewart DA, Gowrishankar TR and Weaver JC. Skin heating and injury by prolonged millimeter-wave exposure: theory based on a skin model coupled to a whole body model and local biochemical release from cells at supraphysiologic temperatures. IEEE Transactions on Plasma Science 2006; 34(4):1480-93. doi: 10.1109/TPS.2006.878996

[12] Sasaki K, Mizuno M, Wake K, Watanabe S. Monte Carlo simulations of skin exposure to electromagnetic field from $10 \mathrm{GHz}$ to $1 \mathrm{THz}$. Physics in Medicine \& Biology 2017; 62(17): 6993-1710. doi: 10.1088/1361-6560/aa81fc

[13] Daniels RC and Heath RW Jr. $60 \mathrm{GHz}$ wireless communications: emerging requirements and design recommendations. IEEE Vehicular Technology Magazine 2007; September: 41-50. doi:10.1109/MVT.2008.915320

[14] Rappaport TS, Sun S, Mayzus R, Zhao H, Azar Y, Wang K, Wong GN, Schulz JK, Samimi M and Gutierrez F. Millimeter wave mobile communications for 5G cellular: it will work! IEEE Access 2013; 1: 235-49. doi: 10.1109/ACCESS.2013.2260813

[15] Thors B, Colombi D, Ying Z, Bolin T, Törnevik C. Exposure to RF emf from array antennas in 5G mobile communication equipment. IEEE Access 2016; 4: 7469-7478. doi: 10.1109/ACCESS.2016.2601145

[16] Xu F, Seffen KA, Lu TJ. Non-Fourier analysis of skin biothermomechanics.International Journal of Heat and Mass Transfer 2008; 51(9-10): 2237-2259. https://doi.org/10.1016/j.ijheatmasstransfer.2007.10.024

[17] Ozen S, Helhel S, Bilgin S. Temperature and burn injury prediction of human skin exposed to microwaves: a model analysis. Radiat Environ Biophys 2011; 50: 483-489. https://doi.org/10.1007/s00411-011-0364-y

[18] Wessapan T, Rattanadecho P. Numerical analysis of specific absorption rate and heat transfer in human head subjected to mobile phone radiation: effects of user age and radiated power. Journal of Heat Transfer 2012; 134: 121101-1-10. doi: 10.1115/1.4006595

[19] Wessapan T, Rattanadecho P. Temperature induced in human organs due to near-field and far-field electromagnetic exposure effects. International Journal of Heat and Mass Transfer 2018; 119: 65-76. https://doi.org/10.1016/j.ijheatmasstransfer.2017.11.088

[20] Shao Z, Fujise M. An improved FDTD formulation for general linear lumped microwave circuits based on matrix theory. IEEE Transactions on Microwave Theory and Techniques 2005; 53(7): 226166.doi:10.1109/TMTT.2005.850450

[21] Lindell IV, Sihvola AH. Perfect Electromagnetic Conductor. Journal of Electromagnetic Waves and Applications 2005, 19(7): 861-869. https://doi.org/10.1163/156939305775468741

[22] Adair ER, Petersen RC. Biological Effects of Radio-Frequency/Microwave Radiation. IEEE Transactions on Microwave Theory and Techniques 2002; 50(3): 953-962. doi:10.1109/22.989978

[23] Kaur J, Khan SA. Thermal changes in human abdomen exposed to microwaves: A model study. Advanced Electromagnetics 2019; 8(3): 64-75. https://doi.org/10.7716/aem.v8i3.1092

[24] Nishizawa S, Hashimoto O. Effectiveness analysis of lossy dielectric shields for a three-layered human model. IEEE Transactions on Microwave Theory and Techniques 1999; 47: 277-283. doi: 10.1109/22.750223

[25] Ney M, Abdulhalim I. Modeling of reflectometric and ellipsometric spectra from the skin in the terahertz and submillimeter waves region. Journal of Biomedical Optics 2011; 16(6): 067006-1-15. https://doi.org/10.1117/1.3592779

[26] Sabbah AI, Dib NI, Al-Nimr MA. Evaluation of specific absorption rate and temperature elevation in a multilayered human head model exposed to radio frequency radiation using the finite-difference time domain method. IET Microw Antennas Propag 2011; 5: 1073-1080. doi: 10.1049/iet-map.2010.0172

[27] Liu XZ, ZhuY, Zhang F, Gong XF. Estimation of temperature elevation generated by ultrasonic irradiation in biological tissues using the thermal wave method. Chin Phys B 2013; 22(2): 024301. DOI: 10.1088/16741056/22/2/024301 doi: 10.1088/1674-1056/22/2/024301

[28] Kizilova N, Korobov A. (2019). Bioheat equation with Fourier and non-Fourier heat transport laws: applicability to heat transfer in human tissues. Journal of Thermal Engineering 2019; 5(6): 149-161. https://doi.org/10.18186/thermal.653915

[29] Pennes HH. Analysis of tissue and arterial blood temperature in the resting human forearm. Journal of Applied Physiology 1948; 1: 93-122. https://doi.org/10.1152/jappl.1948.1.2.93 
[30] Wessapan T, Srisawatdhisukul S, Rattanadecho P. Specific absorption rate and temperature distributions in human head subjected to mobile phone radiation at different frequencies. Int J Heat Mass Transfer 2011; 55: 347359. doi: 10.4103/ijpvm.IJPVM_70_17

[31] Miklavčič D, Pavšelj N, Hart FX. Electric Properties of Tissues. In Wiley Encyclopedia of Biomedical Engineering, 2006. doi:10.1002/9780471740360.ebs0403. accessed on March 17,2019.

[32] Wang Z, Deurenberg P, Wang W, Apietrobelli A, Baumgartner RN, Steven B, Heymsfield SB. Hydration of fatfree body mass: review and critique of a classic body-composition constant. Am. J Clin Nutr 1999; 69: 833-41. https://doi.org/10.1093/ajen/69.5.833

[33] Feldman Y, Puzenko A, Ishai, PB, Caduff A, Davidovich I, Sakran, F, Agranat, AJ. (2009). The electromagnetic response of human skin in the millimetre and submillimetre wave range. Phys Med Biol 2009; 54: 3341-3363. doi: 10.1088/0031-9155/54/11/005

[34] Vague J, Garrigues, JC. Recherchesur la composition du tissuadipeuhumain et notammentsateneur en steroids. Ann Endocrin 1955; 16: 805.

[35] Mitchell HH, Hamilton TS, Steggerda FR, Bean HW. The chemical composition of the adult human body and its bearing on the biochemistry of growth. J biol Chem 1945; 158: 625-637.

[36] Entenman C, Goldwater WH, Ayres NS, Behnke AR Jr. Analysis of adipose tissue in relation to body weight loss in man. J appl Physiol 1958; 13:129-34. https://doi.org/10.1152/jappl.1958.13.1.129 